BMJ Open Sport \& Exercise Medicine

\title{
High-intensity interval training improves obstructive sleep apnoea
}

\author{
Trine Karlsen, ${ }^{1,2}$ Bjarne Martens Nes, ${ }^{1}$ Arnt Erik Tjønna, ${ }^{1}$ Morten Engstrøm,,${ }^{3,4}$ \\ Asbjørn Støylen, ${ }^{5,6}$ Sigurd Steinshamn ${ }^{1,7}$
}

To cite: Karlsen T, Nes BM, Tjønna AE, et al. Highintensity interval training improves obstructive sleep apnoea. BMJ Open Sport Exerc Med 2017;2:e000155. doi:10.1136/bmjsem-2016000155

- Prepublication history and additional material is available. To view please visit the journal (http://dx.doi.org/ 10.1136/bmjsem-2016000155).

Accepted 28 December 2016

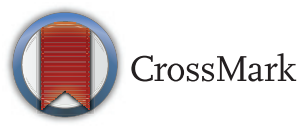

For numbered affiliations see end of article.

Correspondence to

Trine Karlsen; Trine.karlsen@ ntnu.no

\section{ABSTRACT}

Background: Three hours per week of vigorous physical activity is found to be associated with reduced odds of sleep-disordered breathing.

Aim: To investigate whether 12 weeks of highintensity interval training (HIIT) reduced the apnoeahypopnea index (AHI) in obese subjects with moderate-to-severe obstructive sleep apnoea.

Methods: In a prospective randomised controlled exercise study, 30 (body mass index $37 \pm 6 \mathrm{~kg} / \mathrm{m}^{2}$, age $51 \pm 9$ years) patients with sleep apnoea (AHI $41.5 \pm 25.3$ events/hour) were randomised 1:1 to control or 12 weeks of supervised HIIT $(4 \times 4$ min of treadmill running or walking at $90 \%-95 \%$ of maximal heart rate two times per week).

Results: In the HIIT group, the AHI was reduced by $7.5 \pm 11.6$ events/hour (within-group $p<0.05$ ), selfreported sleepiness (Epworth scale) improved from $10.0 \pm 3.6$ to $7.3 \pm 3.7$ (between-group $p<0.05$ ) and maximal oxygen uptake improved from $28.2 \pm 7.4$ to $30.2 \pm 7.7 \mathrm{~mL} / \mathrm{kg} / \mathrm{min}$ (between-group $\mathrm{p}<0.05$ ) from baseline to 12 weeks. The AHI, self-reported sleepiness and $\mathrm{VO}_{2 \text { max }}$ Were unchanged from baseline to 12 weeks in controls (baseline AHI 50.3 \pm 25.5 events/hour, Epworth score 5.9 \pm 4.3 , maximal oxygen uptake $27.0 \pm 6.8 \mathrm{~mL} / \mathrm{kg} / \mathrm{min})$. Body weight remained unchanged in both groups.

Conclusion: Twelve weeks of HIIT improved the AHI and self-reported daytime sleepiness in subjects with obese sleep apnoea without any change in the desaturation index and body weight.

\section{INTRODUCTION}

Obstruction of breathing during sleep due to upper airway collapse, also known as obstructive sleep apnoea (OSA), ${ }^{1}$ is associated with physical inactivity ${ }^{2}{ }^{3}$ and several inactivity-related comorbidities such as obesity, hypertension, type 2 diabetes and cardiovascular disease. ${ }^{4}$ Sleep deprivation and daytime sleepiness are associated with low levels of physical activity ${ }^{5}$ and could induce a vicious cycle of physical inactivity and low exercise motivation, ${ }^{6}$ insomnia and comorbidity clustering.

In a cohort study, questionnaire-based, self-reported vigorous physical activity three times per week or more was found to be

\section{Key messages}

High-intensity exercise training improves:

- The apnoea-hypopnea index

- Self-reported sleepiness

- Maximal oxygen uptake.

What are the new findings?

- High-intensity exercise training improves the apnoea-hypopnea index.

- High-intensity exercise training improves daytime sleepiness.

- High-intensity exercise training is feasible in obese subjects with obstructive sleep apnoea.

How might it impact on clinical practice in the near future?

High-intensity exercise training could be a timeefficient exercise alternative for subjects diagnosed with obstructive sleep apnoea and high cardiovascular comorbid clustering.

associated with reduced odds of developing sleep-disordered breathing. ${ }^{7}$ High-intensity interval training (HIIT) is found superior to moderate exercise in improving cardiovascular disease-related comorbidities and maximal oxygen consumption $\left(\mathrm{VO}_{2 \max }\right)$ in several cardiometabolic high-risk populations. ${ }^{8}{ }^{9}$ As OSA is associated with obesity and several high-risk cardiovascular disease comorbidities, HIIT as a possible treatment of both the obstructive sleep disorder and cardiovascular risk factors should be studied.

Standard treatment with continuous positive airway pressure (CPAP) and reduction in body weight improves airflow obstruction (measured as the apnoea-hypopnea index (AHI)), daytime sleepiness and several OSArelated comorbidities. ${ }^{5}$ However, long-term adherence to both treatments is moderate, ${ }^{5}$ 10 and focus on other positive lifestyle changes is limited. Modest improvements in AHI, self-reported sleepiness, $\mathrm{VO}_{2 \max }$ and quality of life are reported in exercise interventions with moderate intensity, ${ }^{11}{ }^{12}$ in 
combination with breathing exercises, ${ }^{11}$ diet,${ }^{13} \mathrm{CPAP}^{14}$ and strength exercise. ${ }^{12}$ In a meta-analysis, AHI decreased with 6.7 events/hour (32\% reduction) after exercise, independent of change in body weight. ${ }^{15}$

To our knowledge, no study has investigated the effect of HIIT on AHI in subjects diagnosed with OSA. We hypothesised that 12 weeks of two weekly sessions of HIIT would significantly improve AHI in obese patients diagnosed with moderate-to-severe OSA.

\section{MATERIALS AND METHODS}

Thirty subjects with moderate-to-severe OSA were recruited from the Department of Thoracic Medicine at St. Olav's Hospital, Trondheim University Hospital, or through public announcements. After initial screening, patients were randomised 1:1 into HIIT or a control group (CON) through a study-specific web randomisation database at the Unit of Applied Clinical Research, Norwegian University of Science and Technology (webcrf.medisin.ntnu.no). No stratification was used. The inclusion criteria were a body mass index $($ BMI $) \geq 30 \mathrm{~kg} / \mathrm{m}^{2}$ and an AHI $\geq 15$. Exclusion criteria were inability to exercise due to musculoskeletal conditions and known ischemic cardiovascular disease. Figure 1 describes the patient flow in the study.

\section{Ethics}

The study was approved by the Regional Medical Research Ethic Committee (no 2010/1539), registered in the clinical trials database (NCT01215617) and performed according to the Declaration of Helsinki. All subjects signed written informed consent before randomisation in the study.

\section{Protocol}

After the initial screening investigation (baseline) and randomisation, subjects in the HIIT group performed 12 weeks of supervised HIIT, two times per week, while the CON group was encouraged to continue their normal lifestyle. All subjects continued their normal CPAP use. At 12 weeks, postintervention testing of primary and secondary outcomes was performed. The primary study outcome was AHI measured through respiratory polygraphy registrations. Secondary outcomes included: Epworth sleepiness questionnaire (Norwegian version), ${ }^{16}$ $\mathrm{VO}_{2 \max }$, flow-volume spirometry and blood biomarkers.

\section{Exercise training intervention}

HIIT was performed as $4 \times 4$ min of treadmill walking or running at $90 \%-95 \%$ of maximal heart rate $\left(\mathrm{HR}_{\max }\right)$, two times per week, in the department's training facility at St. Olav's Hospital, Trondheim University Hospital. ${ }^{8}$ Each training session started with 10 min of warm-up period at $\sim 70 \%$ of $\mathrm{HR}_{\max }$. Between every interval of $4 \mathrm{~min}$ and after the last interval, the subjects walked at $\sim 70 \%$ of $\mathrm{HR}_{\max }$ for 3 mins. The subjects used heart rate (HR) monitors and their target HR to control exercise intensity and aimed to reach their individual target $\mathrm{HR}$ zone after 1-1.5 min of exercise during each interval. The exercise physiologist supervising all training sessions checked the target HR of the subjects. Treadmill speed or grade was increased throughout the training period to maintain the target exercise intensity.

\section{Sleep evaluation}

Subjects underwent one full night of respiratory polygraphy registrations with ambulatory equipment (Embletta; Embla, Ontario, Canada) at home at baseline and 12 weeks. A research nurse fitted the equipment to the subjects, and patients slept without using CPAP during the nights of the registration. The subjects reported sleeping patterns to the nurse the morning after the registration and answered the Epworth sleepiness questionnaire. Blinded polygraphy analysis was performed by a specialist in clinical neurophysiology using Somnologica studio 5.1 (Micromed Mogliano Veneto, Triveso, Italy). To compensate for the lack of electroencephalography during the registration, limiting scores of hypopneas connected to arousals, respiration was scored according to the slightly modified 'Chicago criteria' (without arousals), ${ }^{17}$ which has a higher sensitivity than the American Academy of Sleep Medicine (AASM) 2007 criteria (comparable to AASM 2012). ${ }^{18-20}$ A drop in oxygen saturation of $4 \%$ or more was defined as a desaturation event.

\section{Cardiopulmonary exercise testing}

To evaluate the effect of the training intervention and to identify the target exercise intensity, a $\mathrm{VO}_{2 \max }$ treadmill running/walking test was performed using indirect breath-by-breath calorimetry (MMX-II; CORTEX Biophysik, Leipzig, Germany). After a 15 min warm-up at $\sim 70 \%$ of $\mathrm{HR}_{\text {max }}$, the test equipment was fitted to the subjects. After 5 mins of submaximal walking, a gradual increase in workload was made until the patients reached exhaustion. Using an individualised protocol, ${ }^{21}$ speed for running $(1 \mathrm{~km} /$ hour $)$ or grade for walking $(2 \%)$ was increased approximately every minute, while grade ( $5 \%$ for running) and speed (4-6.5 km/hour for walking) were maintained. $\mathrm{VO}_{2 \max }$ was defined as the mean of the highest three consecutive $10 \mathrm{~s}$ measurements where the $\mathrm{VO}_{2}$ leveled off despite an increase in intensity and with a respiratory quotient value above 1.10 . HR was recorded continuously, and lactate was measured from a capillary blood sample immediately after the test. HR recovery was calculated as $\mathrm{HR}_{\max }$ minus $\mathrm{HR}$ in 1 min after the end of exercise. Maximal voluntary ventilation (MVV) was estimated according to Wassermann to $40 \mathrm{xFEV} 1 .^{22}$ 


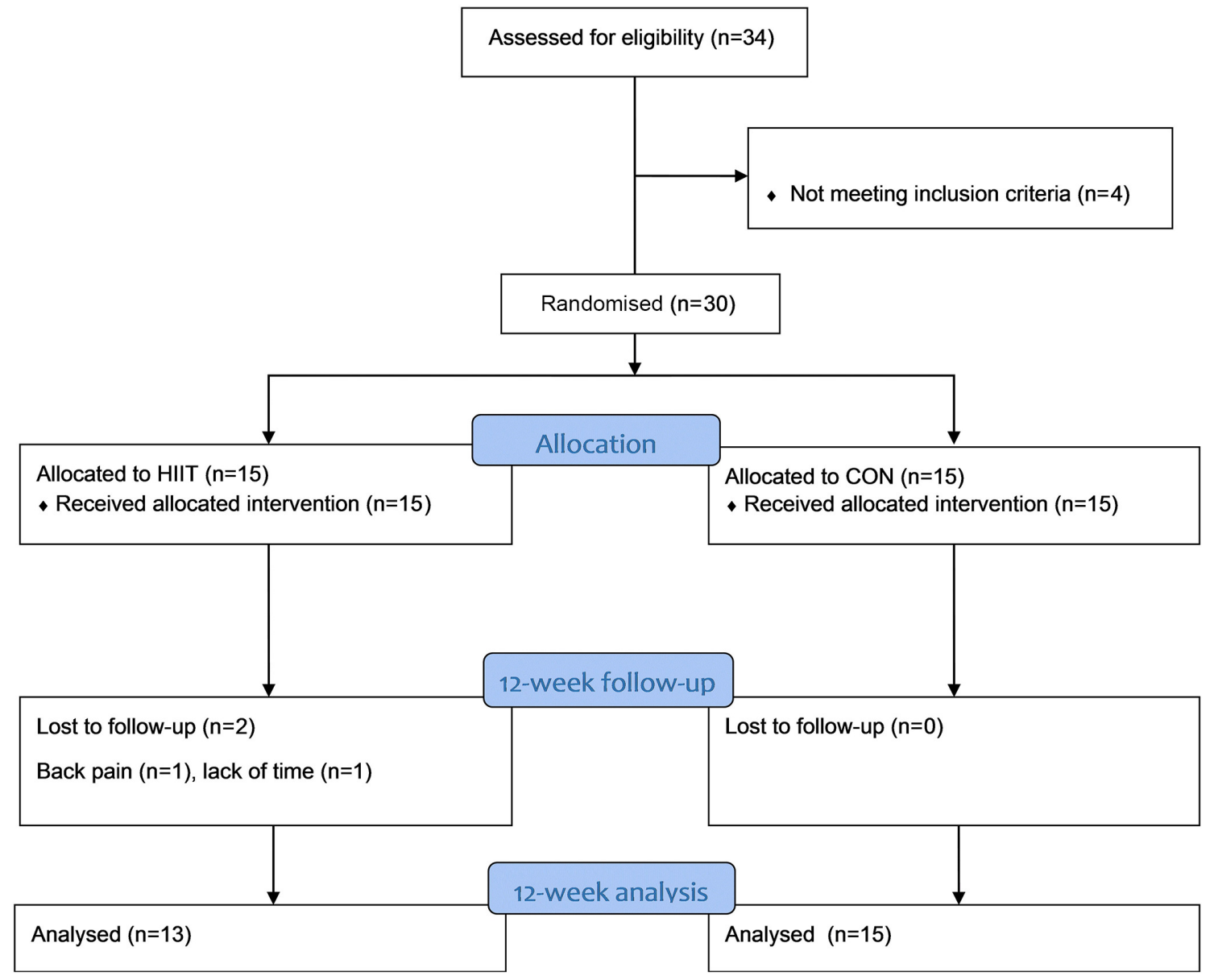

Figure 1 Study flow chart. CON, control group; HIIT, high-intensity interval training.

\section{Clinical measurements}

Body weight and body composition were measured using a bioimpedance scale (Omrun BF500; Omron Healthcare, Kyoto, Japan). Resting HR and systolic and diastolic blood pressure were measured with a polygraph (Tango+; SunTech Medical, Morrisville, North Carolina, USA). Venous plasma and serum samples were collected after overnight fasting for standard haematology and blood biomarker analysis at the Department of Clinical Chemistry, St. Olav's Hospital, Trondheim University Hospital.

\section{Lung function tests}

A research nurse performed spirometry and gas diffusion tests using the Sensormedics Vmax22 Encore (CareFusion, San Diego, California, USA) in accordance with the American Thoracic Society/European Respiratory Society criteria. The spirometer was calibrated daily. The reported value represents the better of at least two acceptable spirometry trials with a variation of less than $150 \mathrm{~mL}$ for forced expiratory volume at $1 \mathrm{~s}$ and forced vital capacity. Diffusing capacity of the lung for carbon monoxide (DLCO) was measured by the single-breath method with a gas mixture containing $0.3 \%$ carbon monoxide and $0.3 \%$ methane. The procedure was repeated with at least $4 \mathrm{~min}$ between each trial up to a maximum of four trials, until two tests of acceptable quality showed DLCO within $3 \mathrm{~mL} / \mathrm{min} /$ $\mathrm{mm} \mathrm{Hg}$ or within $10 \%$ of the highest value, and the mean of these values were recorded.

\section{Statistics}

IBM SPSS version 21 was used for statistical analysis (IBM SPSS Statistics; IBM, New York, USA). The oneway analysis of variance and the repeated-measure analysis of covariance (ANCOVA) were used to test statistical significance within or between groups. Baseline values were used as covariables in the ANCOVA analysis to account for any between-group differences at baseline. A two-sided $\mathrm{p}$ value $\leq 0.05$ was used for statistical significance. The study sample size was based on expectations of an AHI reduction of $4 \pm 5$ events/ hour, $80 \%$ power and a two-sided $\mathrm{p}$ value of $5 \%$, requiring 15 subjects in each group.

\section{RESULTS}

\section{Baseline characteristics}

Table 1 describes the baseline characteristics. Despite using a randomisation database, by chance, AHI was significantly lower, and the Epworth score was significantly higher in the HIIT group compared with CON at baseline $(\mathrm{p} \leq 0.05)$. There were no significant 
Table 1 Baseline characteristics

\begin{tabular}{|c|c|c|}
\hline Variable & HIIT $(n=13)$ & $\operatorname{CON}(n=15)$ \\
\hline Gender (women/men) & $4 / 9$ & $3 / 12$ \\
\hline Age (years) & $52.5 \pm 7.4$ & $49.9 \pm 9.7$ \\
\hline Body weight (kg) & $121 \pm 27$ & $118 \pm 22$ \\
\hline $\mathrm{BMI}\left(\mathrm{kg} / \mathrm{m}^{2}\right)$ & $38.5 \pm 7.0$ & $37.7 \pm 4.8$ \\
\hline Fat mass (\%) & $39.5 \pm 9.2$ & $38.1 \pm 7.3$ \\
\hline Skeletal muscle mass (\%) & $27.9 \pm 3.7$ & $28.1 \pm 3.6$ \\
\hline Resting heart rate (beats/min) & $86 \pm 13$ & $84 \pm 13$ \\
\hline Systolic blood pressure $(\mathrm{mm} \mathrm{Hg})$ & $133 \pm 16$ & $138 \pm 15$ \\
\hline Diastolic blood pressure (mm Hg) & $80 \pm 13$ & $84 \pm 10$ \\
\hline Sleep apnoea duration (months) & $51 \pm 49$ & $88 \pm 58$ \\
\hline CPAP users $(n)$ & 11 & 12 \\
\hline Atrial fibrillation $(n)$ & 2 & 0 \\
\hline Hypertension (n) & 5 & 4 \\
\hline Diabetes type 1 or $2(n / n)$ & $1 / 1$ & $1 / 2$ \\
\hline $\mathrm{AHI}$ (events/hour) & $31.4 \pm 21.7$ * & $50.3 \pm 25.5$ \\
\hline Epworth score & $10.0 \pm 3.6$ * & $5.9 \pm 4.3$ \\
\hline $\mathrm{O}_{2}$ saturation $(\%)$ & $92.4 \pm 1.6$ & $91.6 \pm 1.6$ \\
\hline $\mathrm{O}_{2}$ desaturation events (n/hour) & $36.9 \pm 18.6$ & $55.8 \pm 28.6$ \\
\hline Insulin (pmol/L) & $120.4 \pm 64.5$ & $149.6 \pm 127.4$ \\
\hline Cholesterol (mmol/L) & $5.2 \pm 1.0$ & $5.3 \pm 1.2$ \\
\hline LDL (mmol/L) & $3.3 \pm 0.9$ & $3.3 \pm 1.1$ \\
\hline $\mathrm{HDL}(\mathrm{mmol} / \mathrm{L})$ & $1.2 \pm 0.2$ & $1.1 \pm 0.3$ \\
\hline Triglycerides (mmol/L) & $1.53 \pm 0.65$ & $1.94 \pm 1.05$ \\
\hline Leptin (pmol/L) & $1747 \pm 1419$ & $1657 \pm 1261$ \\
\hline HbA1c (\%) & $5.8 \pm 0.3$ & $5.9 \pm 0.6$ \\
\hline CRP (mg/L) & $6.3 \pm 2.1$ & $8.3 \pm 7.2$ \\
\hline TSH (mU/L) & $1.76 \pm 0.72$ & $2.21 \pm 0.85$ \\
\hline T4 (pmol/L) & $15.7 \pm 2.2$ & $15.2 \pm 2.0$ \\
\hline $\mathrm{Hb}(\mathrm{g} / \mathrm{dL})$ & $14.5 \pm 1.0$ & $14.9 \pm 1.5$ \\
\hline HCT (\%) & $43 \pm 3$ & $43 \pm 4$ \\
\hline FVC (L) & $4.31 \pm 0.87$ & $4.38 \pm 0.77$ \\
\hline Predicted FVC (\%) & $92.4 \pm 12.4$ & $91.3 \pm 15.3$ \\
\hline FEV1 (L) & $3.36 \pm 0.57$ & $3.39 \pm 0.58$ \\
\hline Predicted FEV1 (\%) & $88.3 \pm 10.0$ & $86.6 \pm 14.3$ \\
\hline IVC (L) & $4.22 \pm 0.93$ & $4.34 \pm 0.79$ \\
\hline Predicted IVC (\%) & $96.1 \pm 18.6$ & $91.4 \pm 16.2$ \\
\hline FEV1/FVC & $78.3 \pm 4.3$ & $76.3 \pm 4.5$ \\
\hline TLCO (mmol/min//kPa) & $10.4 \pm 1.6$ & $9.8 \pm 2.1$ \\
\hline Predicted TLCO (\%) & $102.9 \pm 13.04$ & $95.3 \pm 15.7$ \\
\hline $\mathrm{KCO}(\mathrm{mmol} / \mathrm{min} / \mathrm{kPa})$ & $1.78 \pm 0.17$ & $1.63 \pm 0.24$ \\
\hline Predicted KCO (\%) & $119 \pm 12$ & $109 \pm 16$ \\
\hline
\end{tabular}

Description of subjects at study baseline, including demographics, sleep evaluation, blood and clinical biomarkers and pulmonary function. *Significant group difference at baseline $(p \leq 0.05)$.

$\mathrm{AHI}$, apnoea-hypopnea index; BMI, body mass index; CON, control group; CPAP, continuous positive airway pressure; CRP, C reactive protein; FEV1, forced expiratory volume in $1 \mathrm{~s}$; FVC, forced vital capacity; Hb, haemoglobin; HCT, haematocrit; HBA1C, glycolysed haemoglobin A1c; HDL, high-density lipoprotein; HITT, high-intensity interval training; IVC, inspiratory vital capacity; KCO, transfer coefficient; LDL, low-density lipoprotein cholesterol; $\mathrm{O}_{2}$, oxygen; TSH, thyroid-stimulating hormone; T4, thyroxin; TLCO, single-breath transfer factor of the lung/pulmonary diffusion capacity.

differences between groups in the remaining variables at baseline. At 12 weeks, total body fat in the HIIT group $(\sim 2 \%)$ and skeletal muscle mass in the CON group $(\sim 1 \%)$ were significantly reduced from baseline $(\mathrm{p} \leq 0.05)$. There was no significant between-group changes in BMI. Leptin was significantly reduced from $1747 \pm 1419$ to $1412 \pm 1047 \mathrm{pmol} / \mathrm{L}$ from baseline to 12 weeks in the HIIT group $(p=0.015)$, with no statistical 
change in control (12-week leptin $1276 \pm 594 \mathrm{pmol} / \mathrm{L}$ $(p=0.393))$. There were no statistical changes in clinical biomarkers from blood, blood pressure, flow-volume spirometry or pulmonary diffusion capacity in the HIIT or CON group from baseline to 12 weeks (12week data not shown).

\section{Sleep data}

Twelve weeks of HIIT improved AHI by $24 \%(\mathrm{p} \leq 0.05)$, with no change in the CON group. There was no between-group difference in AHI from the baseline to the 12-week follow-up $(p=0.2)$ (figure 2A). The Epworth self-reported sleepiness scale was significantly improved in the HIIT group compared with the CON group $(\mathrm{p} \leq 0.05)$ at 12 weeks (figure $2 \mathrm{~B})$. There was no change in nightly oxygen saturation or number of desaturation events in the HIIT or CON groups from baseline to 12 weeks (figure 2C,D). None of the subjects reported change in CPAP use during the intervention.

\section{Cardiopulmonary exercise testing}

$\mathrm{VO}_{2 \max }$ increased by $2.0 \mathrm{~mL} / \mathrm{kg} / \mathrm{min}$ in the HIIT group at 12-week testing and was significantly improved compared with the CON group $(\mathrm{p} \leq 0.05)$. The change in $\mathrm{VO}_{2 \max }$ did not correlate with the change in AHI $(\mathrm{r}=-0.11)$. Maximal ventilation (VE) was increased in the HIIT group at 12 weeks $(\mathrm{p} \leq 0.05)$ (table 2$)$. As

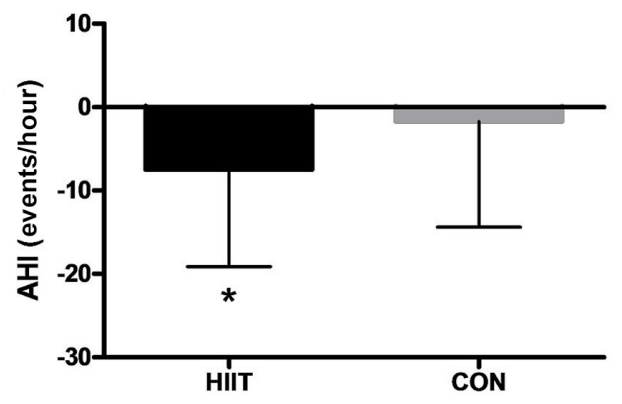

A

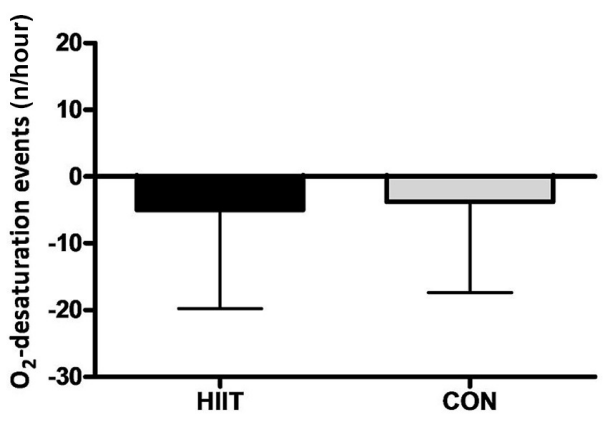

C the maximal VE increased at 12 weeks in the HIIT group, the breathing reserve was decreased and the VE/MVV ratio increased and was significantly different from the CON group at 12 weeks $(\mathrm{p} \leq 0.05)$ (table 2$)$.

\section{Exercise intervention}

Subjects in the HIIT group performed $21 \pm 3$ supervised training sessions (88\% compliance). The mean exercise HR was $151 \pm 16$ beats/min $(92 \%$ of $\left.\mathrm{HR}_{\text {max }}\right)$. The exercise $\mathrm{HR}$ was within the target zone and unchanged throughout the 12 weeks of supervised exercise. Two subjects in the HIIT group dropped out of training after 8 and 11 training sessions-one due to lack of time and one due to lower back pain.

\section{DISCUSSION}

The main finding in this study was that 12 weeks of HIIT significantly improved AHI within the group, while the desaturation index remained stable. The improvement in AHI was accompanied by a significant improvement in the self-reported Epworth sleepiness score in the HIIT group compared with the CON group. Improvement in obstructive breathing during sleep most likely improved sleep quality and, therefore, also reduced self-reported daytime sleepiness in the HIIT group, with no significant changes in the CON group. The $24 \%$ improvement in AHI was modest and

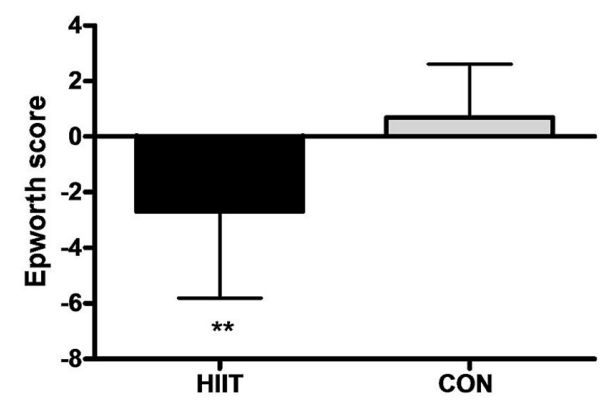

B

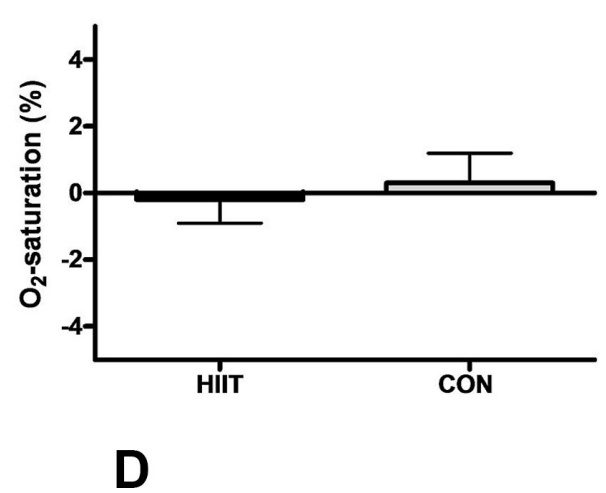

Figure 2 Change in $\mathrm{AHI}(\mathrm{A})$, oxygen desaturation index $(\mathrm{C})$ and oxygen saturation (D) measured by respiratory polygraphy and self-reported daytime sleepiness measured with the Epworth scale (B) from baseline to 12 weeks. *Significant within-group difference from baseline $(p \leq 0.05)$; ${ }^{\star}$ Significant between-group difference after the intervention $(p \leq 0.05)$. AHI, apnoeahypopnea index; CON, control group; HIIT, high-intensity interval training. 
Table 2 Cardiopulmonary exercise testing

\begin{tabular}{|c|c|c|c|c|}
\hline \multirow[t]{2}{*}{ Variables } & \multicolumn{2}{|c|}{ HIIT } & \multicolumn{2}{|c|}{ CON } \\
\hline & Baseline & 12 weeks & Baseline & 12 weeks \\
\hline $\mathrm{VO}_{2 \max }(\mathrm{mL} / \mathrm{kg} / / \mathrm{min})$ & $28.2 \pm 7.4$ & $30.2 \pm 7.7^{*} \dagger$ & $27.0 \pm 6.8$ & $27.0 \pm 5.1$ \\
\hline $\mathrm{VO}_{2 \max }(\mathrm{L} / \mathrm{min})$ & $3.28 \pm 0.60$ & $3.48 \pm 0.61^{*}$ & $3.14 \pm 0.80$ & $3.26 \pm 0.73$ \\
\hline $\mathrm{VE}(\mathrm{L} / \mathrm{min})$ & $111.5 \pm 26.5$ & $119.3 \pm 22.7$ * & $99.0 \pm 24.4$ & $104.1 \pm 18.8$ \\
\hline$R Q$ & $1.11 \pm 0.07$ & $1.11 \pm 0.08$ & $1.08 \pm 0.07$ & $1.10 \pm 0.07$ \\
\hline $\mathrm{HR}_{\max }$ (beats/min) & $165 \pm 16$ & $164 \pm 18$ & $159 \pm 19$ & $161 \pm 22$ \\
\hline HRR (beats/min) & $28.3 \pm 9.6$ & $29.2 \pm 15.0$ & $29.1 \pm 12.3$ & $32.5 \pm 8.4$ \\
\hline $\mathrm{O}_{2}$ puls (mL/beats) & $19.9 \pm 3.5$ & $21.4 \pm 3.9$ * & $19.6 \pm 3.8$ & $20.2 \pm 3.7$ \\
\hline Lactate $(\mathrm{mmol} / \mathrm{L})$ & $9.2 \pm 2.9$ & $10.5 \pm 2.5$ & $8.2 \pm 2.8$ & $7.4 \pm 2.7$ \\
\hline VE/VCO2@AT & $27.3 \pm 2.7$ & $28.4 \pm 2.5$ & $25.4 \pm 2.8$ & $26.7 \pm 2.9$ \\
\hline MVV & $134.3 \pm 22.7$ & $128.6 \pm 24.2$ & $135.7 \pm 23.0$ & $133.9 \pm 22.0$ \\
\hline Breathing reserve (L/min) & $22.8 \pm 18.2$ & $10.1 \pm 15.0 \dagger$ & $36.7 \pm 24.3$ & $30.9 \pm 12.5$ \\
\hline VE/MVV & $0.83 \pm 0.13$ & $0.93 \pm 0.12 \dagger$ & $0.74 \pm 0.15$ & $0.77 \pm 0.84$ \\
\hline
\end{tabular}

Results from cardiopulmonary exercise testing at baseline and 12 weeks.

*Significant within-group difference from baseline $(p \leq 0.05)$.

$\dagger$ Significant between-group difference after the intervention $(p \leq 0.05)$.

$\mathrm{HR}_{\text {max }}$, maximal heart rate; $\mathrm{HRR}, 1$ min heart rate recovery; $\mathrm{MVV}$, estimated maximal voluntary ventilation; $\mathrm{O}_{2}$ puls, maximal oxygen pulse; RQ, respiratory quotient; VE/VCO2@AT, equivalent of ventilation and carbon dioxide expiration at anaerobic threshold, VE, ventilation; $\mathrm{VE} / \mathrm{MVV}$, breathing reserve ratio; $\mathrm{VO}_{2 \max }$, maximal oxygen uptake.

comparable to changes seen after moderate exercise training. ${ }^{15}$

Several mechanisms for improvement in AHI with moderate exercise training have been discussed. There was no change in body weight after HIIT. Hence, weight reduction per se is not the underlying mechanism for AHI improvement. ${ }^{11} 12$ The HIIT group did display a small decrease in total body fat $(2 \%)$, with no significant change in muscle mass. Reduced body fat in the pharyngeal/neck region could improve upper airway airflow. ${ }^{1}$ Increased physical activity could improve venous blood flow and reduce daytime leg oedema, resulting in reduced upper airway night-time oedema and improved upper airway airflow and AHI during sleep ${ }^{23}$; however, we cannot confirm these mechanisms in our study.

An interaction of leptin with sleep-disturbed breathing has been discussed. ${ }^{24}$ Leptin is highly associated with OSA and obesity, ${ }^{125}$ and CPAP treatment reduces leptin levels. ${ }^{26}$ We found a decrease in serum leptin after HIIT in our subjects, where the majority were CPAP users. The change in leptin did not correlate with the change in AHI $(\mathrm{r}=-0.21)$, and there were no group differences. Elevated leptin is associated with reduced ventilatory control and hypoventilation in obese patients with $\mathrm{OSA},{ }^{27}$ and leptin replacement reverses hypoventilation in a leptin-deficient obesemice model $^{28}$; hence, interaction between exercise, leptin and OSA should further be investigated.

Risk factors such as blood biomarkers and blood pressure were normal at baseline and did not change with exercise, indicating that our subjects were well medically managed at inclusion. HIIT increased $\mathrm{VO}_{2 \max }$ by $7 \%$. The increase in $\mathrm{VO}_{2 \max }$ is similar to comparable fit populations performing HIIT $^{29}{ }^{30}$ but somewhat lower than studies of cardiovascular disease patients with lower baseline $\mathrm{VO}_{2 \max } \cdot{ }^{8}$ The difference in improvement between studies could be due to the baseline $\mathrm{VO}_{2 \max }$ level, the number of weekly sessions (only two sessions per week were used in the current study, while the majority of other studies have used three weekly sessions ${ }^{89}{ }^{30}$ ) or the importance of training intensity, where exercising above $92 \%$ of $\mathrm{HR}_{\max }$ was found to improve $\mathrm{VO}_{2 \max }$ the most in patients with coronary artery disease. ${ }^{31}$ Low $\mathrm{VO}_{2 \max }$ is one of the strongest prognostic factors for future cardiovascular disease and premature all-cause mortality, ${ }^{32} 33$ independent of obesity. ${ }^{34} 35$ As OSA is strongly associated with obesity and elevated cardiovascular disease risk, improving $\mathrm{VO}_{2 \max }$, transforming patients with OSA from 'unfit and fat' to 'fit and fat' is a feasible risk reduction strategy. ${ }^{36}$ We found no correlation between the change in $\mathrm{VO}_{2 \max }$ and $\mathrm{AHI}$ in our study; therefore, the effect of HIIT on AHI is most likely unrelated to improved cardiopulmonary fitness measured as $\mathrm{VO}_{2 \max }$. None of the subjects were limited in their exercise performance by pulmonary diseases, as resting pulmonary function and diffusion capacity were normal at baseline and did not change at 12 weeks (table 1). ${ }^{11}$ To explain the effect of HIIT on AHI and sleep quality, other mechanisms (as discussed above) should be explored further.

\section{Strengths and limitations}

We had no electroencephalogram (EEG) data and could not score arousals during sleep. However, all registrations were interpreted according to the same criteria and blinded for intervention allocation. We scored respiratory polygraphy registrations according to 'Chicago criteria', ${ }^{17}$ which permit scoring of 
hypopneas without the accompanied desaturations or arousals (lack of EEG electrodes). It is uncertain if improved respiration during sleep would have been detected if conservative hypopnea criteria had been chosen. Criteria for scoring of respiration during sleep to diagnose OSA have been widely discussed. ${ }^{34} 3738$ Using the most liberal criteria when comparing several registrations over time seems adequate in our study, both to compensate for the lack of EEG electrodes in registrations and to optimise the ability to detect any changes from preintervention to postintervention. The accompanied reduction of Epworth score indicates that the effect was clinically relevant.

The primary study parameter, AHI, was significantly higher in CON compared with HIIT at baseline despite the use of a randomisation database. In retrospect, stratification for AHI should have been done in the randomisation process. As the CON group did have significantly higher AHI than the HIIT group at baseline, one could argue that the decrease in AHI in the HIIT group is present despite a moderate baseline $\mathrm{AHI}$ and due to the intervention, and not due to high baseline values causing a larger statistical regression towards the mean with repeated measures, as seen in the CON group. To account for baseline group differences, ANCOVA analysis with baseline as a covariable was used for group comparison. The study did not control for the effect of training intensity, as it lacks a moderate-exercise training group. Therefore, we cannot conclude if the effect of training on OSA is dependent on exercise intensity.

\section{CONCLUSION}

Twelve weeks of HIIT two times per week significantly improves the AHI, self-reported daytime sleepiness and maximal oxygen uptake in obese patients with sleep apnoea without any change in body weight. The improvement in AHI was modest and independent of increase in $\mathrm{VO}_{2 \max }$, indicating that physical activity per se might be important for improvement in sleep quality in patients with sleep apnoea.

\section{PERSPECTIVES}

We have demonstrated that HIIT is a feasible treatment to improve AHI and reduced daytime sleepiness on top of standard CPAP treatment in subjects with moderate-to-severe OSA. To our knowledge, this is the first study on the effects of high-intensity exercise in subjects with OSA. Future studies should compare the effects of high-intensity and moderate-intensity exercises and different training volumes as data from the follow-up period indicates positive effects of moderateintensity exercise as well. In addition, further investigations of the underlying mechanisms behind the positive effect of exercise training on sleep obstruction are warranted.
Author affiliations

${ }^{1} \mathrm{~K}$.G. Jebsen Center of Exercise in Medicine, Department of Circulation and Medical Imaging, Norwegian University of Science and Technology,

Trondheim, Norway

${ }^{2}$ St. Olavs Hospital, Trondheim University Hospital, Trondheim, Norway

${ }^{3}$ Department of Neurology and Clinical Neurophysiology, St. Olav's Hospital,

Trondheim University Hospital, Trondheim, Norway

${ }^{4}$ Department of Neuroscience, Norwegian University of Science and

Technology, Trondheim, Norway

${ }^{5}$ Department of Cardiology, St. Olav's Hospital, Trondheim University Hospital, Trondheim, Norway

${ }^{6}$ Department of Circulation and Medical Imaging, Norwegian University of Science and Technology, Norway

${ }^{7}$ Department of Thoracic Medicine, St. Olav's Hospital, Trondheim University Hospital, Trondheim, Norway

Acknowledgements We are highly grateful to the Unit of Applied Clinical Research, to the medical faculty at the Norwegian University of Science and Technology for supplying the webCRF randomisation database and to the research nurses Marit Tjelle Setvik and Anne Stine Fossum for their assistance with the data collection. In addition, we are highly grateful to our research subjects for devoting their time to participate in the study.

Contributors All authors meet the criteria for authorship defined by the International Committee of Medical Journal Editors.

Funding The SINTEF Unimed foundation partly funded the study.

Competing interests None declared.

Ethics approval The study was approved by the Regional Medical Research Ethic Committee (no 2010/1539), registered in the clinical trials database (NCT01215617) and performed according to the Declaration of Helsinki.

Provenance and peer review Not commissioned; externally peer reviewed.

Data sharing statement Unpublished data in the study will be prepared and submitted for peer review after the publication of the current paper.

Open Access This is an Open Access article distributed in accordance with the Creative Commons Attribution Non Commercial (CC BY-NC 4.0) license, which permits others to distribute, remix, adapt, build upon this work noncommercially, and license their derivative works on different terms, provided the original work is properly cited and the use is non-commercial. See: http:// creativecommons.org/licenses/by-nc/4.0/

\section{REFERENCES}

1. Young T, Peppard PE, Taheri S. Excess weight and sleepdisordered breathing. J Appl Physiol 2005;99:1592-9.

2. Peppard PE, Young T. Exercise and sleep-disordered breathing: an association independent of body habitus. Sleep 2004;27:480-4.

3. Igelström H, Emtner M, Lindberg $\mathrm{E}$, et al. Physical activity and sedentary time in persons with obstructive sleep apnea and overweight enrolled in a randomized controlled trial for enhanced physical activity and healthy eating. Sleep Breath 2013;17:1257-66.

4. Tiengo A, Fadini GP, Avogaro A. The metabolic syndrome, diabetes and lung dysfunction. Diabetes Metab 2008;34:447-54.

5. Fritscher LG, Mottin CC, Canani S, et al. Obesity and obstructive sleep apnea-hypopnea syndrome: the impact of bariatric surgery. Obes Surg 2007;17:95-9.

6. Smith SS, Doyle G, Pascoe T, et al. Intention to exercise in patients with obstructive sleep apnea. J Clin Sleep Med 2007;3:689-94.

7. Quan SF, O'Connor GT, Quan JS, et al. Association of physical activity with sleep-disordered breathing. Sleep Breath 2007;11:149-57.

8. Rognmo $\varnothing$, Hetland E, Helgerud J, et al. High intensity aerobic interval exercise is superior to moderate intensity exercise for increasing aerobic capacity in patients with coronary artery disease. Eur J Cardiovasc Prev Rehabil 2004;11:216-22.

9. Tjønna AE, Lee SJ, Rognmo Ø, et al. Aerobic interval training versus continuous moderate exercise as a treatment for the metabolic syndrome: a pilot study. Circulation 2008;118:346-54.

10. Leinum CJ, Dopp JM, Morgan BJ. Sleep-disordered breathing and obesity: pathophysiology, complications, and treatment. Nutr Clin Pract 2009;24:675-87. 
11. Sengul YS, Ozalevli S, Oztura I, et al. The effect of exercise on obstructive sleep apnea: a randomized and controlled trial. Sleep Breath 2011;15:49-56.

12. Giebelhaus V, Strohl KP, Lormes W, et al. Physical exercise as an adjunct therapy in sleep Apnea-An open trial. Sleep Breath 2000;4:173-6.

13. Norman JF, Von Essen SG, Fuchs RH, et al. Exercise training effect on obstructive sleep apnea syndrome. Sleep Res Online 2000;3:121-9.

14. Ackel-D'Elia C, da Silva AC, Silva RS, et al. Effects of exercise training associated with continuous positive airway pressure treatment in patients with obstructive sleep apnea syndrome. Sleep Breath 2012;16:723-35.

15. Iftikhar IH, Kline CE, Youngstedt SD. Effects of exercise training on sleep apnea: a meta-analysis. Lung 2014;192:175-84.

16. Pallesen $\mathrm{S}$, Nordhus $\mathrm{IH}$, Omvik $\mathrm{S}$, et al. Prevalence and risk factors of subjective sleepiness in the general adult population. Sleep 2007;30:619-24.

17. AASM. Sleep-related breathing disorders in adults: recommendations for syndrome definition and measurement techniques in clinical research. The Report of an American Academy of Sleep Medicine Task Force. Sleep 1999;22:667-89.

18. Iber C, Ancoli-Israel S, Chesson A, et al. Rules, terminology and technical specifications. The AASM Manual for the Scoring of Sleep and Associated Events. 1st edn. Westchester, IL: American Academy of Sleep Medicine, 2007:1-59.

19. Ruehland WR, Rochford PD, O'Donoghue FJ, et al. The new AASM criteria for scoring hypopneas: impact on the apnea hypopnea index. Sleep 2009;32:150-7.

20. Berry RB, Brooks R, Gamaldo CE. Rules, terminology and technical specifications. The AASM Manual for the Scoring of Sleep and Associated Events. 2nd edn. Westchester, IL: American Academy of Sleep Medicine, 2012.

21. Fletcher GF, Ades PA, Kligfield $\mathrm{P}$, et al. Exercise standards for testing and training: a scientific statement from the American Heart Association. Circulation 2013;128:873-934.

22. Whipp K-G. Principles of exercise testing and interpretation including pathophysiology and clinical applications. 5th edn. Philadelphia: Lippincott Williams \& Wilkins, 2012.

23. White LH, Bradley TD. Role of nocturnal rostral fluid shift in the pathogenesis of obstructive and central sleep apnoea. J Physiol 2013;591:1179-93.

24. Fitzpatrick M. Leptin and the obesity hypoventilation syndrome: a leap of faith? Thorax 2002;57:1-2.
25. Phillips BG, Kato M, Narkiewicz K, et al. Increases in leptin levels, sympathetic drive, and weight gain in obstructive sleep apnea. $A m \mathrm{~J}$ Physiol Heart Circ Physiol 2000;279:H234-7.

26. Sanner BM, Kollhosser P, Buechner N, et al. Influence of treatment on leptin levels in patients with obstructive sleep apnoea. Eur Respir $J$ 2004;23:601-4.

27. Phipps PR, Starritt E, Caterson I, et al. Association of serum leptin with hypoventilation in human obesity. Thorax 2002;57:75-6.

28. Tankersley C, Kleeberger S, Russ B, et al. Modified control of breathing in genetically obese (ob/ob) mice. J Appl Physiol(1985) 1996;81:716-23.

29. Bækkerud FH, Solberg F, Leinan IM, et al. Comparison of three popular exercise modalities on VO2max in overweight and obese. Med Sci Sports Exerc 2016;48:491-8.

30. Zisko N, Stensvold D, Hordnes-Slagsvold K, et al. Effect of change in VO2max on daily total energy expenditure in a cohort of norwegian men: a randomized pilot study. Open Cardiovasc Med J 2015;9:50-7.

31. Moholdt T, Madssen E, Rognmo $\varnothing$, et al. The higher the better? Interval training intensity in coronary heart disease. J Sci Med Sport 2014;17:506-10.

32. Kodama S, Saito K, Tanaka S, et al. Cardiorespiratory fitness as a quantitative predictor of all-cause mortality and cardiovascular events in healthy men and women: a meta-analysis. JAMA 2009;301:2024-35.

33. Myers J, Prakash M, Froelicher V, et al. Exercise capacity and mortality among men referred for exercise testing. $N$ Engl $\mathrm{J}$ Med 2002;346:793-801.

34. Lee DC, Sui X, Artero EG, et al. Long-term effects of changes in cardiorespiratory fitness and body mass index on all-cause and cardiovascular disease mortality in men: the aerobics center longitudinal study. Circulation 2011;124:2483-90.

35. Lee S, Kuk JL, Katzmarzyk PT, et al. Cardiorespiratory fitness attenuates metabolic risk independent of abdominal subcutaneous and visceral fat in men. Diabetes Care 2005;28:895-901.

36. Lavie CJ, De Schutter A, Milani RV. Healthy obese versus unhealthy lean: the obesity paradox. Nat Rev Endocrinol 2015;11:55-62.

37. BaHammam AS, Obeidat A, Barataman $\mathrm{K}$, et al. A comparison between the AASM 2012 and 2007 definitions for detecting hypopnea. Sleep Breath 2014:18:767-73.

38. Guilleminault C, Hagen CC, Huynh NT. Comparison of hypopnea definitions in lean patients with known obstructive sleep apnea hypopnea syndrome (OSAHS). Sleep Breath 2009;13:341-7. 